\title{
“Evolución Académica de la carrera de Ingeniería Agroindustrial, UNI Sede Regional Norte, período 2005-2012"
}

\author{
Luis María Dicovosky - Docente Investigador y Subdirector de la UNI Sede Regional del Norte
}

\section{Resumen}

La Universidad Nacional de Ingeniería, UNI, consciente de su responsabilidad histórica y con apego a su Visión, Misión, Principios y a su profunda vocación social, y dada la demanda creciente de las carreras de ingeniería por los jóvenes bachilleres del norte del país, en marzo de 2005, en Estelí, apertura su primera sede Regional con cuatro carreras, entre estas estaba Ingeniería Agroindustrial, la primera en su tipo a nivel nacional. La carrera estaba estructurada por 58 asignaturas con 214 créditos UNI, el pensum hace énfasis en el desarrollo de capacidades de investigación y en la realización de prácticas profesionales. En el 2005 se inicia con un grupo de primer año y al año 2012, 395 estudiantes habían ingresaron al programa. En el 2011 se hace la primera autoevaluación de la carrera con fines de mejora para una futura acreditación regional. Para comprender la evolución del rendimiento académico en la carrera, se modelaron estadísticamente las variables de la base de datos de registro académico. Se observó en los datos que los estudiantes mejoraron significativamente su rendimiento académico desde el 2005 hasta 2010, sin embargo partir de este año se fueron uniformando los criterios de evaluación académica en los diferentes tipos de asignaturas, cerrándose las brechas de rendimiento académico, por otro lado los docentes con formación pedagógica han tenido más estudiantes con alto rendimientos y menos con bajo rendimiento.

Palabras clave: registro académico, rendimiento académico, autoevaluación, pedagogía

\section{Introducción}

En el año 2011 se realiza el primer proceso de autoevaluación de la carrera de Ingeniería
Agroindustrial con base en el manual de acreditación de la Agencia Centroamericana de Acreditación de Programas de Arquitectura e Ingeniería (ACAAl) y con fines de implementar un plan de mejora que permita acreditar la carrera en el 2013 ante esta agencia. Dentro de las actividades pendientes a mejorar está la evaluación y seguimiento del proceso enseñanza aprendizaje para permitir implementar instrumentos que brinden seguimiento a estudiantes de bajo, medio y alto rendimiento. (UNINorte, Proceso de Autoevaluación del Programa de Ingeniería Agroindustrial, 2012). Esta investigación aporta datos relevantes sobre las causas que han incidido en el rendimiento académico histórico de la carrera de Ingeniería Agroindustrial y da pistas para un plan de mejora.

La finalidad del estudio fue describir a partir de variables cuantitativas modeladas estadísticamente, la evolución del comportamiento académico en los estudiantes de Ingeniería Agroindustrial, desde la apertura carrera hasta el año actual, con la finalidad de aportar pistas sobre medidas a implementar en su primer plan de mejora con fines de acreditación.

\section{Materiales y métodos}

A solicitud de la comisión de mejora de carrera el Sistema de Registro Académico de la Sede UNI Norte de Estelí facilitó la base de datos histórica de registros académicos de la carrera de Ingeniería Agroindustrial, 10,581 registros en formato de tabla de Excel. De la base de datos se filtró los estudiantes desertores de las asignaturas, nota final de "0". Se organizó la información en variables que pudieran haber incidido en el rendimiento académico. Para comparar los promedios de la variable "notas" se utilizó un Modelo Lineal Mixto con control de la heterocedasticidad, los datos expresados en proporciones se analizaron como 
variables binarias en Modelos Lineales Generalizados Mixtos. Las comparaciones de medias se hicieron por la prueba DGC (Alfa=0.05)(Di Rienzo, Macchivelli, \& Casanoves, Modelos Lineales Mixtos, aplicaciones en InfoStat, 2012). El software estadístico empleado fue InfoStat.

\section{Resultados y discusión}

Cuando se graficó la evolución del Rendimiento Académico de la Carrera de Ingeniería Agroindustrial en las Variables "Notas Finales por Asignatura" y "Proporción de Aprobados" ambas desagregadas por "Tipo de Asignatura:Administrativas, Ciencias BásicasMatemáticas, Ingenierías y Complementarias", se observaron valores altos y estables a partir del año 2010. Los bajos rendimientos de los primeros años se pueden interpretar por el hecho de que en esos años se estaba conformando la planta docente especializada y que es hasta el 2009 que se completan los cinco años de la carrera. También se observa que los problemas en las Asignaturas Básica y Matemáticas se fueron mejorando con los años y que la brecha inicial entre los diferentes tipos de asignaturas se comienza a superar a partir del 2010, ya no habiendo diferencias en el 2012. Ver figuras 1 y 2.

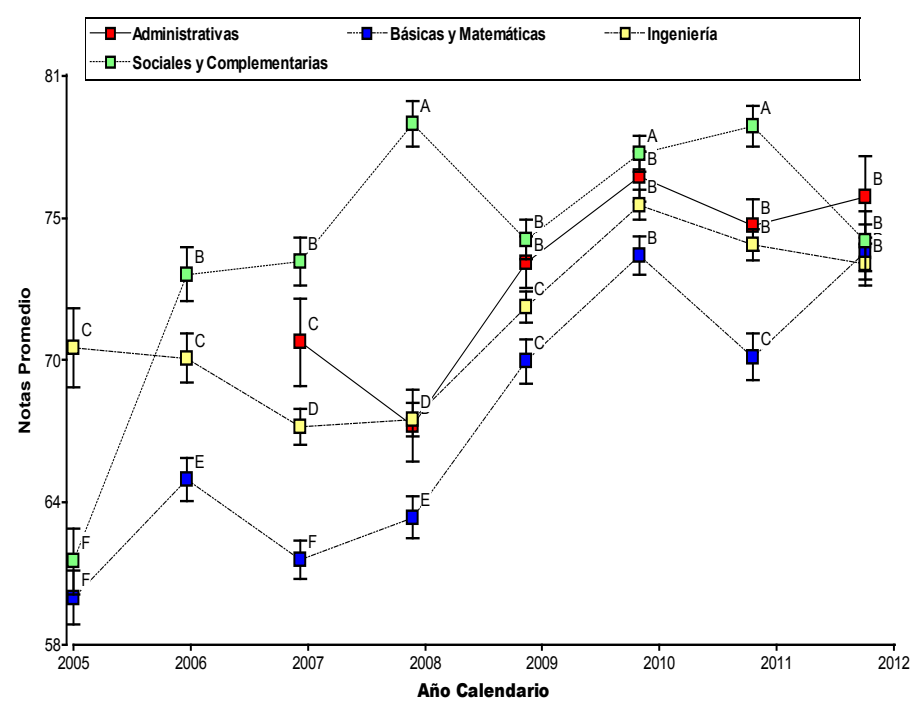

Letras iguales promedios iguales. Las barras representan los Errores Estándares, EE.

Figura 1. Notas Promedios y tipo de asignatura

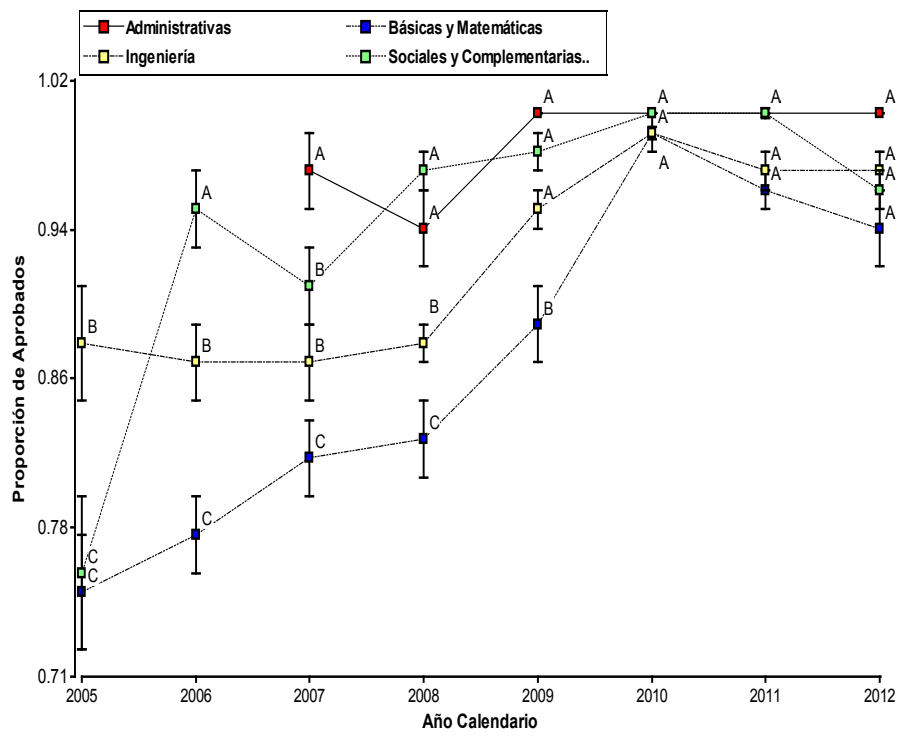

Letras iguales promedios iguales Las barras representan los EE.

Figura 2. Proporción de Aprobados y tipo de asignatura

Al agrupar las notas de los estudiantes en tres niveles de rendimiento: Alto 81-100, Medio 6180 y Bajo menos de 61 puntos, se observó una tendencia de aumento de los estudiantes de alto rendimiento desde el 2005 hasta el 2010, donde se estabilizan, algo inverso ocurrió con los estudiantes de bajo rendimiento. La proporción de estudiantes de rendimiento medio se ha mantenido estable en el tiempo, Ver figura 3.

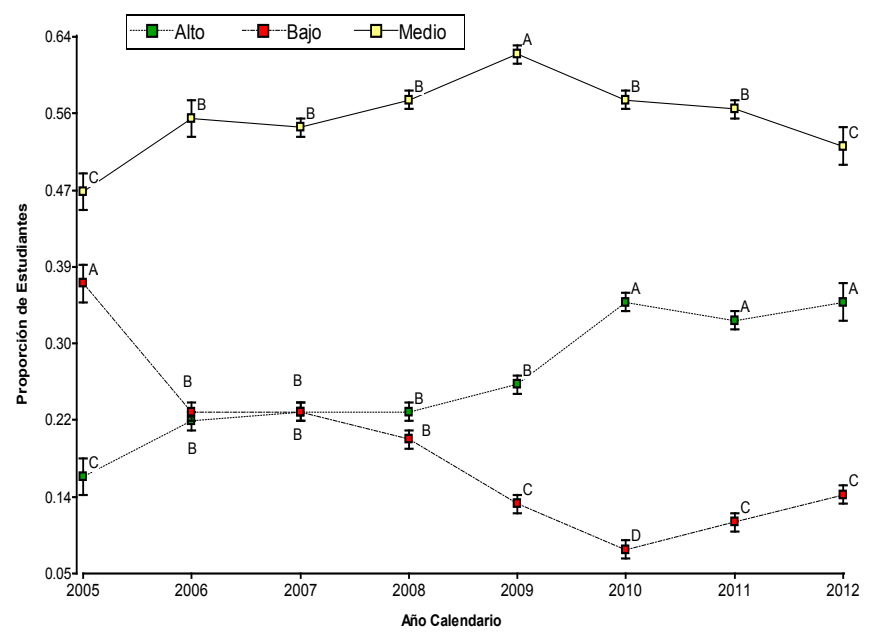

Letras iguales promedios iguales por tipo de rendimiento. Las barras representan los EE.

Figura 3. Proporción de Estudiantes por Tipo de Rendimiento 
Académico: Alto, Medio y Bajo

Cuando los docentes se agruparon en dos tipos: "Con Formación Docente", los licenciados en Ciencias de la Educación y los "Docentes Empíricos", la mayoría Ingenieros. Se encontró en ambos grupos un comportamiento semejante en el tiempo, en cuanto a "promedio de notas" y "proporción de aprobados", pero si se observó diferencias en las proporciones de estudiantes con notas altas o bajas, parecería que los docentes con formación pedagógica discriminaron mejor las notas extremas y que los docentes empíricos tendieron a tener una mayor proporción de estudiantes con nota media, Ver figura 4.

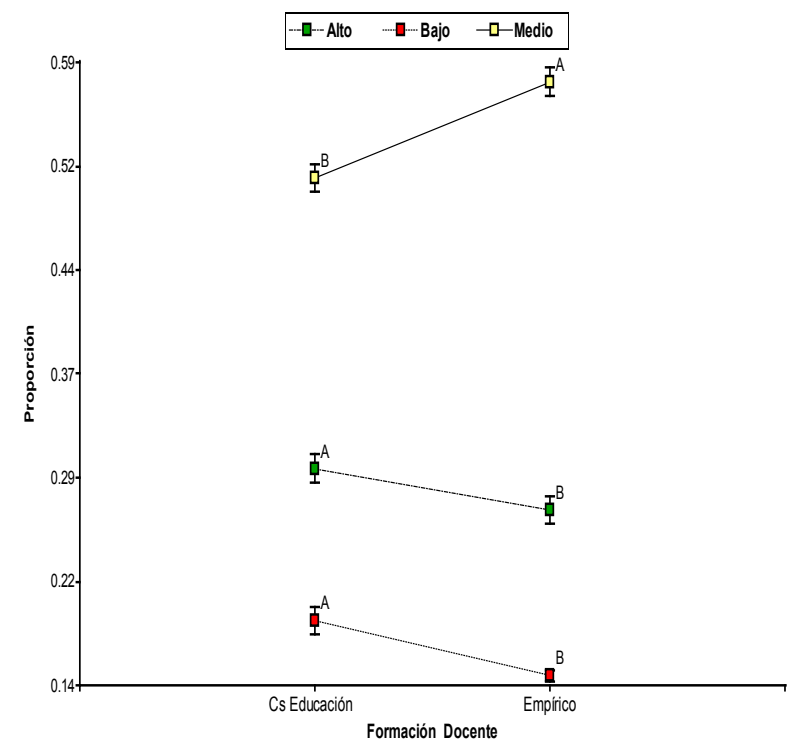

Letras iguales promedios iguales en cada tipo de rendimiento. Las barras representan los EE.

Figura 4. "Formación docente" y"Tipo de Rendimiento Académico: Alto, Medio y Bajo"

\section{Conclusiones}

Los estudiantes mejoraron significativamente su rendimiento académico desde el 2005 hasta 2010, sin embargo partir de este año se fueron uniformando los criterios de evaluación académica en los diferentes tipos de asignaturas (Básicas Matemáticas, Administrativas, Sociales e propias de las Ingenierías) no encontrándose diferencias en el 2012. Es importante comentar que a partir del 2010 la mayoría de los docentes comienzan un diplomado en educación universitaria con el IPN de México, lo cual pudo haber impactado en el cierre de brechas de rendimiento académico entre los diferentes tipos de asignatura.

\section{Referencias}

Di Rienzo, J., Macchivelli, R., \& Casanoves, F. (2012). Modelos Lineales Mixtos, aplicaciones en InfoStat. Córdoba: Grupo InfoStat.

UNINorte. (2007). Plan de Carrera de Agroindustria. Estelí: UNI.

UNINorte. (2012). Proceso de Autoevaluación del Programa de Ingeniería Agroindustrial. Estelí: UNI. 